\title{
A RELAÇÃO TRANSFERENCIAL PARA ALÉM DA INTERPRETAÇÃO: REFLEXÕES A PARTIR DA TEORIA DE WINNICOTT
}

Livia Milhomem Januário e Maria Izabel Tafuri

Lívia Milhomem Januário Mestra e doutoranda em psicologia clínica e cultura na Universidade de Brasília (UnB), pesquisadora do Laboratório de Psicopatologia e Psicanálise do Instituto de Psicologia da UnB.

Maria Izabel Tafuri Doutora em psicologia clínica, professora adjunta de psicologia clínica na UnB, coordenadora do Laboratório de Psicopatologia e Psicanálise do Instituto de Psicologia da UnB.
RESUMO: Este artigo reflete sobre a importância de pensar a relação transferencial na clínica psicanalítica para além da interpretação. Para isso, utiliza-se a concepção de Winnicott como referencial teórico, sendo ressaltadas a noção de holding, a regressão à dependência e a questão do uso de objetos e sua influência sobre a técnica da interpretação. Winnicott revela que na clínica com alguns pacientes, em especial os autistas e psicóticos, o objetivo da análise, antes de fornecer interpretações, é proporcionar um ambiente suficientemente bom a partir do qual o sujeito pode retomar o processo de constituição de si mesmo e da externalidade do mundo.

Palavras-chaves: transferência, interpretação, holding, Winnicott.

\begin{abstract}
The transferencial relation beyond the interpretation: reflections from the theory of Winnicott. This article reflects about the importance of thinking the transferencial relation in the psychoanalytic clinic beyond the interpretation. For this, the Winnicott's concept is used as theoretical reference, highlighting the concept of holding, regression to dependence and the question of the use of objects and its influence on the technique of interpretation. Winnicott shows that in the clinic, with some patients, particularly autistic and psychotic, before providing interpretation, the objective of the analysis is to provide a good environment from which the subject can retake the constitution process of himself/herself and of the externality of the world..
\end{abstract}

Keywords: Transference, interpretation, holding, Winnicott. 


\section{INTRODUÇÃO}

O fato de a psicanálise fazer da linguagem o seu material primordial, e da interpretação a sua técnica de trabalho, pode levar à ideia de que ela negligencia outros aspectos da transferência, privilegiando exclusivamente o âmbito verbal. Alguns psicanalistas tendem a circunscrever a experiência analítica a uma leitura das representações dos processos psíquicos, excluindo do campo psicanalítico o que não é passível de representação no âmbito da linguagem. Dessa forma, o lugar do analista fica sendo apenas o de intérprete.

Contudo, Freud (1937/1996) já havia enfatizado que o uso da transferência deve sempre visar à totalidade do tratamento e não ao ato interpretativo em si, compreendendo que o trabalho interpretativo deve estar a serviço do paciente, originando-se dele e sendo destinado a ele.

Assim, Roudinesco e Plon (1998) explicam que Freud, tentando temperar a onipotência da interpretação no processo analítico, propôs uma ampliação em seu campo de escuta, seguindo em direção a outro processo: o da construção. O processo de construção não exclui o trabalho interpretativo, mas é dirigido ao que não é lembrado, ao irrepresentável, levando assim à questão das possibilidades e dos limites da interpretação e do que pode ser interpretável durante a análise.

Embora haja uma expectativa de prevalência do verbal na análise, tanto da parte do analista quanto do paciente, existe continuamente outro nível de comunicação - o não-verbal — que pode sustentar, negar ou impedir o trabalho analítico. Na clínica com pacientes autistas e psicóticos isso se torna ainda mais evidente, e o analista é com frequência enviado aos limites da técnica da interpretação. Diante disso, alguns analistas, em especial os que se dedicam à análise de crianças e ao estudo da constituição psíquica do sujeito, geram contribuições ao estudo da relação transferencial para além da interpretação.

Winnicott é um desses autores que, ao destacar vários aspectos no processo de análise, como o holding, a regressão à dependência e o uso de objetos, revela a importância do papel do analista para além da interpretação. Winnicott realiza uma distinção fundamental entre um recurso técnico - a interpretação - e a realização de um trabalho de análise, explicando que o processo de análise não se restringe à interpretação. Em suas palavras:

“A análise não consiste apenas no exercício de uma técnica. É algo que nos tornamos capazes de fazer quando alcançamos um certo estágio na aquisição da técnica básica. Aquilo que passamos a poder fazer é cooperar com o paciente no seguimento de um processo, processo este que em cada paciente possui o seu próprio ritmo e caminha no seu próprio rumo. Todos os aspectos importantes desse processo originam-se no paciente, e não em nós enquanto analistas.” (WINNICOTT, 1955/2000, p.374) 
Nesse trabalho, discutimos algumas das contribuições de Winnicott, refletindo sobre o lugar do analista na relação transferencial para além da interpretação. Para isso, ressaltamos a noção de holding, a regressão à dependência e a questão do uso de objetos e sua influência sobre a técnica da interpretação.

\section{A NOÇÃO DE HOLDING}

Winnicott, por meio de sua prática clínica e dos estudos sobre a constituição psíquica do sujeito, pôde compreender alguns dos momentos que ocorrem ao longo da análise de alguns pacientes. Ele observa que na análise de fases ou de momentos psicóticos "não é possível considerar o ego uma entidade estabelecida. Não pode, então existir também uma neurose de transferência, para a qual certamente é preciso que haja um ego.” (WINNICOTT, 1956/2000, p.394). Quando há "um ego intacto e o analista pode ter certeza sobre a qualidade dos cuidados iniciais, o contexto analítico revela-se menos importante que o trabalho interpretativo" (idem, p.395). Nesse caso, realiza-se uma psicanálise clássica, na qual o objetivo do trabalho de análise consiste em trazer para a consciência aquilo que estava inconsciente por meio da interpretação da revivência que ocorre na relação transferencial.

Contudo, quando o ego ainda não é uma entidade, Winnicott revela que os pacientes "não esperam que a análise os torne mais conscientes, mas aos poucos eles podem vir a ter esperança de que lhes seja possível sentir-se reais" (WINNICOTT, 1988/1990, p.79). Nesse caso, o contexto (setting/ambiente) torna-se mais importante que a interpretação, e a manutenção de uma situação adaptativa ao ego é fundamental.

Há, assim, dois tipos de clínica, o que leva Winnicott (1955/2000) a dividir a contribuição de Freud em duas partes: 1) a técnica psicanalítica na qual o material do paciente deve ser compreendido e interpretado; e 2) o setting no qual esse trabalho é realizado. Apesar de atencioso em relação aos detalhes do setting, Freud não teoriza analisando-o como foco, o que, em contrapartida, é realizado por Winnicott, que o considera essencial na clínica psicanalítica.

Winnicott (1955/2000) esclarece que Freud desenvolve a psicanálise a partir de determinadas situações clínicas nas quais é possível chegar ao complexo de Édipo e lidar com relacionamentos interpessoais. Para Winnicott, os casos clínicos de Freud tinham recebido os cuidados adequados na primeira infância e as experiências infantis do próprio Freud foram suficientemente boas, o que fez com que, em sua autoanálise, tomasse a maternagem do bebê como algo evidente por si mesmo.

Porém Winnicott, por meio do seu trabalho com mães e com bebês, descobre a diferença entre um ambiente bom e um ambiente que falha. Ele se depara com situações clínicas anteriores ao complexo de Édipo, nas quais o indivíduo 
ainda não se constituiu como pessoa integrada e separada, não consegue viver no próprio corpo e se relacionar com objetos. Aqui, têm-se agonias intoleráveis de aniquilamento, e não ansiedades de castração ou de separação. São casos clínicos que não obtiveram um "ambiente suficientemente bom" a partir do qual o sujeito pudesse se constituir. São pacientes até então não acolhidos pela psicanálise clássica.

Diante disso, Winnicott (1955/2000) propõe três variedades de clínica com base em diferentes registros de sofrimento, decorrentes de diferentes momentos de falhas no processo maturacional e que demandam modos distintos e específicos de trabalho clínico.

A primeira variedade clínica refere-se a pacientes que funcionam como pessoas inteiras e às dificuldades que se localizam no âmbito dos relacionamentos interpessoais. Nesse caso, a técnica de trabalho é a mesma desenvolvida por Freud. Recorre-se ao setting clássico freudiano, utilizando como ferramenta básica a interpretação da transferência com o intuito de trazer à luz o material inconsciente recalcado.

A segunda é a clínica com pacientes que começaram a se integrar, mas que ainda não conquistaram a estabilidade no seu sentido de unidade. A análise, nesse caso, tem a ver não só com a aquisição desta unidade, como também à junção do amor e do ódio e ao reconhecimento da dependência. O elemento mais importante aqui é a sobrevivência do analista na condição do fator dinâmico. Para Winnicott, a técnica, nesse tipo de trabalho, não difere da primeira categoria, mas surgem novos problemas com relação ao manejo, havendo, assim, a junção do manejo aos princípios da análise clássica.

A terceira clínica relaciona-se a estágios iniciais do desenvolvimento emocional e a períodos anteriores ao estabelecimento da personalidade como uma entidade. A estrutura pessoal ainda não está integrada e é anterior à aquisição da unidade pessoal em termos de espaço e tempo. Nesse caso, a ênfase recai sobre o manejo clínico e o estabelecimento do setting. Essa clínica é caracterizada por uma complexa organização de holding que permite, sem necessariamente recorrer à interpretação, a regressão à dependência.

A noção de holding na teoria winnicottiana é de extrema importância para o manejo clínico e é compreendida como sustentação - sustentam-se determinadas experiências ao longo de um tempo sem interromper a experiência do paciente. Significa oferecer um ambiente/setting que sustente e permita o processo de integração do sujeito.

Para Winnicott, "esse holding, como a tarefa da mãe no cuidado do lactente, reconhece tacitamente a tendência do paciente a se desintegrar, a cessar de existir, a cair para sempre" (WINNICOTT, 1963a/1983, p.217). Se o holding é encontrado, esses sentimentos agonizantes podem ser transformados em experiências 
positivas, o que leva Safra (1995) a explicar que, nesse caso, a desintegração pode ser vivida como um relaxamento e um repouso, cair para sempre passa a ser a alegria no movimento de ser carregado e morrer transforma-se em uma boa sensação de estar vivo, enfim: o holding fornece ao indivíduo a confiança na realidade e nos contatos humanos.

Margaret Little, ao relatar sua análise pessoal com Winnicott, revela que as sessões eram caracterizadas por poucas interpretações e pelo holding, que é ilustrado por ela metafórica e literalmente:

\footnotetext{
"Metaforicamente ele estava controlando (holding) a situação, dando apoio, mantendo contato em todos os níveis com qualquer coisa que estivesse acontecendo, dentro e ao redor do paciente e no relacionamento com ele.

Literalmente, durante intermináveis horas ele segurou as minhas duas mãos apertadas entre as dele, quase como um cordão umbilical, enquanto eu ficava deitada, frequentemente escondida debaixo do cobertor, calada, inerte, retraída, apavorada, com raiva ou em lágrimas, dormindo e às vezes sonhando.” (LITTLE, 1990, p.46)
}

Em casos extremos, talvez seja necessário que, em algum momento da análise, o holding assuma uma forma física, mas Winnicott relaciona esse cuidado com a compreensão do sofrimento do paciente e da expressão dessa compreensão, de modo que o paciente se sinta sustentado pelo analista: "toda vez que compreendemos profundamente um paciente, e o mostramos através de uma interpretação correta e feita no momento certo, estamos de fato sustentando o paciente" (WINNICOTT, 1954/2000, p.354).

Winnicott (1972/1991) ilustra a função do holding ao descrever o caso clínico de um paciente de trinta anos. Nesse livro, o autor revela a função do holding tanto na sustentação do processo analítico - sustentando ao longo do tempo as experiências do paciente - quanto na integração dessas experiências no tempo e no espaço, já que, em alguns momentos, as interpretações de Winnicott visavam integrar as experiências ocorridas tanto no setting analítico quanto no ambiente externo.

Assim, Winnicott revela que na clínica com pacientes autistas e psicóticos, antes de fornecer interpretações, o objetivo da análise é proporcionar um "ambiente suficientemente bom”, que se adapte à necessidade que surge do ser e dos processos de maturação, de modo que se permita o surgimento de um ego, o abandono de organizações defensivas e a retomada do processo de amadurecimento.

Para isso, é necessário que a análise propicie as condições que faltaram nos momentos das falhas ambientais e que impediram o desenvolvimento saudável. Deve-se ainda levar em consideração que cada período do amadurecimento 
requer condições diferentes, o que leva a modificações no trabalho de análise de acordo com as necessidades de cada paciente em relação a determinado ponto do amadurecimento. A análise é vista como a satisfação das necessidades com base na noção de holding, o que mostra outra forma de trabalho na qual, até então, o principal instrumento de trabalho era a interpretação.

Winnicott postula que, em determinadas situações clínicas, as interpretações relativas aos conteúdos da sessão produziriam um efeito nocivo quando se considera, por exemplo, a intrusão que uma interpretação transferencial clássica representaria ao mostrar o analista como outro não-eu para um paciente que o necessita, ainda, como fazendo parte de si mesmo. Nesse caso, o analista "teria sido um mau analista fazendo uma boa interpretação" (WINNICOTT, 1962/1983, p.228).

O autor utiliza a noção de ambiente-holding para descrever o setting analítico. Em termos de relação analítica é, o setting, a atenção dispensada pelo analista, juntamente com o trabalho interpretativo que criam o ambiente de holding que norteia as necessidades psicológicas e físicas do pacientes. Esse setting, que inclui o analista, é um ambiente que evoca estabilidade, confiança e esperança para que o paciente possa vir a se constituir como sujeito. O setting compreendido desta forma "vai sendo gradualmente percebido pelo paciente como algo que faz nascer a esperança de que o self verdadeiro possa finalmente ser capaz de assumir os riscos que o início da experiência de viver implica." (WINNICOTT, 1956/2000, p.486).

\section{A "REGRESSÃO À DEPENDÊNCIA" NA TRANSFERÊNCIA}

Para Winnicott, a regressão faz parte do processo de análise e é fundamental na clínica com pacientes em sofrimento psíquico grave. O autor mostra que a "regressão à dependência” ocorre a partir da existência de uma falha ambiental e de uma crença inconsciente - que pode tornar-se uma esperança consciente - de que, em algum momento futuro, haverá a oportunidade para uma nova experiência, na qual a situação de falha poderá ser revivida, agora dentro de um ambiente capaz de prover a adaptação adequada.

Não é adequado utilizar o termo regressão, proposto por Winnicott, toda vez que um comportamento infantil se faz presente. É necessário que se distinga a “regressão à dependência" do paciente regredido. A primeira está relacionada ao paciente que, estando em análise, regride à dependência em função da relação transferencial. O segundo se refere ao paciente que ainda não pôde alcançar a maturidade do desenvolvimento emocional, provavelmente por causa de uma falha ambiental precoce.

$\mathrm{Na}$ "regressão à dependência” há um retorno a um estágio inicial do desenvolvimento cuja característica básica é uma determinada organização de ego 
frente à e uma ameaça de caos, tornando-se necessário que o ego se organize para que o paciente possa enfrentar o caos que se anuncia. Em outras palavras, é preciso que o paciente tenha uma capacidade interna (organização interna) que o possibilite fazer uso do fato de estar regredido. Winnicott aponta para dois aspectos dessa organização: uma falha de adaptação por parte do ambiente que resulta no desenvolvimento do "falso self", e uma crença na possibilidade de uma correção dessa falha original representada por uma capacidade latente de regressão que envolve uma complexa organização egoica.

A regressão ocorre dentro do contexto da relação transferencial, uma vez que o holding tenha sido estabelecido no setting analítico e o paciente seja capaz de depositar confiança no analista. O analista, enquanto sujeito presente, mas não intrusivo, que espera e que respeita as defesas do paciente, acena como esperança de um novo começo, de um "ser e continuar sendo".

A regressão traz a possibilidade de corrigir uma adaptação inadequada à necessidade do paciente na sua infância precoce. $\mathrm{O}$ ambiente procura atender à necessidade do paciente expressa na transferência na situação analítica de retorno à situação inicial de fracasso ambiental e de uma possível experiência de provisão ambiental adequada. Enquanto a análise clássica necessita que o analista interprete ideias e sentimentos de amor, de ódio, de ambivalência, tais como aparecem na neurose de transferência, nesse caso a análise exige que o analista seja capaz de suportar e de apoiar a regressão real à dependência infantil.

Diante disso, Winnicott introduz uma nova variedade clínica de transferência tendo a identificação primária como mecanismo fundamental, na qual é esperado to que o analista, em sua adaptação suficientemente boa, se transforme no objeto subjetivo de seu paciente. Assim, o analista é concebido segundo a necessidade de constituição e de amadurecimento do indivíduo que como objeto subjetivo dá suporte à esperança, o que leva Safra (2003) a afirmar que um dos lugares do analista na clínica psicanalítica é o de experiência de sonho, "sonho de si mesmo".

Winnicott se refere à relação transferencial nessa clínica afirmando que uma das características da transferência é o fato de que devemos permitir que o passado do paciente se torne presente. Isto porque enquanto na neurose de transferência o passado comparece na análise, neste tipo de trabalho "o presente retorna ao passado, e é o passado. O analista encontra-se, assim, confrontado com o processo primário do pacientes na situação em que esse processo tinha o seu valor original” (WINNICOTT, 1956/2000, p.396).

Nesses casos, Winnicott traz para reflexão "a diferença entre a aceitação pelo analista da realidade da dependência, e seu trabalho com ela na transferência" (WINNICOTT, 1960/1983, p.42). Nessas situações clínicas, a transferência é dominada pela necessidade do paciente de regredir à dependência infantil, 
e as situações em que o ambiente falha aparecem na transferência, o que leva o paciente a reviver os estágios mais precoces na transferência com o analista.

Diante dessa situação clínica, Winnicott afirma que o desfecho bem-sucedido da análise "depende não da compreensão, pelo paciente, do significado das defesas, mas sim de sua capacidade, através da análise e na transferência, de reexperienciar esta ansiedade intolerável em função da qual as defesas foram organizadas.”(WINNICOTT, 1961/2005, p.60). Além da agonia, os “colapsos clínicos reais da primeira infância devem ser relembrados através de sua revivência na transferência” (idem).

Winnicott explica que o medo clínico do colapso na verdade "é o medo de um colapso que já foi experienciado" (WINNICOTT, 1963c/2005, p.72). O autor mostra que o medo do colapso é um medo da agonia primitiva e original (retorno a um estado não-integrado, cair para sempre, perda do conluio psicossomático, perda do senso do real, perda da capacidade de se relacionar com objetos) "que provocou a organização de defesa que o paciente apresenta como síndrome da doença." (idem, p.72).

O intuito de Winnicott é chamar a atenção para a possibilidade de que o colapso já tenha acontecido e que, assim, o paciente precisa 'lembrar'. Contudo, "não é possível lembrar algo que ainda não aconteceu, e esta coisa do passado não aconteceu ainda, porque o paciente não estava lá para que ela lhe acontecesse" (WINNICOTT, 1963c/2005, p.74). Dessa forma, a única maneira de o paciente 'lembrar' é “experienciar esta coisa passada pela primeira vez no presente, ou seja, na transferência. Esta coisa passada e futura torna-se então uma questão do aqui e agora, e é experienciada pelo paciente pela primeira vez.” (idem).

Winnicott revela que "existem momentos em que se precisa dizer a um paciente que o colapso, do qual o medo destrói-lhe a vida, já aconteceu” (WINNICOTT, 1963c/2005, p.73). O autor explica que a experiência original da agonia primitiva não pode cair no passado, a menos que o ego possa primeiro reuni-la dentro de sua própria e atual experiência temporal e do controle onipotente agora, presumindo a função de apoio de ego auxiliar da mãe, ou do analista.

Para Winnicott, em um tratamento bem-sucedido, o paciente precisa pôr em cena o trauma ou o fracasso ambiental e experienciá-lo dentro da área de onipotência pessoal, o que é sempre uma vivência extremamente dolorosa para ele. A regressão a um estado de dependência extrema é um risco que o paciente só ousa enfrentar em uma condição de confiabilidade.

Dias (1999) afirma que as agonias impensáveis não podem pertencer ao passado a menos que possam ser experienciadas pela primeira vez no presente, e que a necessidade específica do paciente é que, dessa vez, a falha aconteça e, com a ajuda do analista, seja percebida como falha do ambiente.

Nas palavras de Winnicott: 
"se o paciente estiver preparado para algum tipo de aceitação deste tipo esquisito de verdade, de que o que ainda não foi experienciado apesar disso aconteceu no passado, irá se abrir o caminho para que a agonia seja experienciada na transferência, na reação às falhas e equívocos do analista. Em doses que não sejam excessivas, o paciente pode lidar com estas últimas, e explicar cada falha técnica do analista como contratransferência. Em outras palavras, o paciente gradualmente reúne o fracasso original do meio ambiente facilitador dentro de sua área de onipotência e da experiência de onipotência que pertence ao estado de dependência (fato transferencial).” (WINNICOTT, 1963c/2005, p.73)

Margaret Little ao escrever não só do ponto de vista de uma paciente como também da perspectiva de uma psicanalista, resume que:

"Do ponto de vista do analista, o valor da regressão para a dependência pode ser afirmado de um modo muito simples - ela é um meio pelo qual se podem explorar as áreas onde predominam as ansiedades psicóticas, revelar experiências antigas, e reconhecer e resolver ideias ilusórias ocultas, através da associação transferência/contratransferência de analista e analisando, em fases positivas e negativas. Na prática, é claro, isso não é tão simples.” (LITTLE, 1990, p.83)

Por meio do exposto e das citações de Winnicott e de Little, percebe-se que a "regressão à dependência" possibilita alcançar pontos do desenvolvimento emocional do indivíduo nos quais estão cristalizadas experiências de agonias, de tal forma que essas experiências possam ser reveladas, presenciadas e testemunhadas na relação transferencial com o analista.

Além disso, a "regressão à dependência" permite a revelação de experiências vividas antes da capacidade de representar, em um período em que não existiam palavras, e que, assim, só podem ser lembradas pelo paciente por meio de experiências sensoriais não-verbais, já que são experiências marcadas na corporeidade do sujeito. A ênfase, então, está na noção de experiência por meio da qual as elas podem ser vividas e referidas, a história de vida do paciente.

Por fim, a "regressão à dependência" permite que o paciente perceba que uma determinada falha ambiental ocorreu a partir do meio ambiente e não a partir de si mesmo. A experiência de onipotência do paciente tende a incorporar em si a falha do ambiente. Daí a importância da utilização do erro do analista, a partir do qual o paciente pode reconhecer não só a falha do analista como a falha do ambiente, sem se responsabilizar por elas.

Nas situações de "regressão à dependência”, a análise reativa um momento de dependência, e o próprio analista se envolve no papel do fracasso se transformando nos pais/ambiente que falharam/falhou. Winnicott revela que a falha do analista na transferência é um componente essencial, pois traz uma reordenação 
das situações de falha precoce. As falhas do analista podem ser pequenas, induzidas pelo paciente ou produzidas por elementos transferenciais delirantes. Com essa falha, tem-se um processo importante na análise: o paciente pode odiar "o analista pela falha que originalmente ocorreu como um fator ambiental, fora da área de controle onipotente pelo lactante, mas que agora é apresentada na transferência” (WINNICOTT, 1962/1983, p.233). Dessa forma, o analista tem êxito por falhar no sentido do paciente.

Winnicott chama a atenção para o fato de que no momento que o paciente se apodera da falha original e se zanga com ela, também pode usar as falhas do analista. Essa falha deve ser tratada como uma falha antiga, e o analista precisa usar suas falhas em termos de significação para o paciente, sendo necessário que o analista assuma responsabilidade sobre suas falhas. Se o analista se defende, "o paciente perde a chance de zangar-se com uma falha passada justamente no momento em que a raiva tornou-se possível pela primeira vez" (WINNICOTT, 1956/2000, p.397).

O analista deve procurar os seus próprios erros toda vez que surge uma resistência, pois é somente pela utilização de seus erros que ele pode realizar a parte mais importante do trabalho: possibilitar que o paciente sinta raiva das falhas ambientais que provocaram rupturas na continuidade do ser. Segundo Winnicott, essa parte do trabalho é a que liberta o paciente da dependência ao analista.

Observa-se então que um dos lugares do analista nessa clínica é o lugar da mãe/ambiente que originalmente falhou nos cuidados de seu bebê. Uma das implicações do analista ao ocupar esse lugar é a possibilidade do paciente experienciar os afetos oriundos dessa situação e, não sendo retaliado, poder iniciar o uso do analista.

Winnicott alerta que esse é um trabalho que exige muito do analista. O analista deve ser sensível às necessidades do paciente e estar disposto a fornecer uma situação que dê conta dessas necessidades, já que o analista não é a mãe natural do paciente. Além disso, o analista deve procurar os seus próprios erros toda vez que surge uma resistência, pois é somente pela utilização de suas falhas que ele pode realizar a parte mais importante do trabalho, possibilitando que o paciente sinta raiva das falhas ambientais que provocaram rupturas na continuidade do ser.

\section{O USO DE OBJETOS E SUA INFLUÊNCIA SOBRE A TÉCNICA DA INTERPRETAÇÃO}

Winnicott (1968a/2005) afirma que o paciente não apenas transfere como também usa criativamente o analista. O papel do analista é ser usado pelo sujeito. O uso é um fenômeno ambiental e não apenas uma projeção, e o analista então funciona como objeto e ambiente. Contudo, para usar um objeto, é necessário ter desenvolvido esta capacidade (de usar objetos), o que faz parte da mudança 
para o princípio da realidade — é uma conquista no crescimento emocional e depende de um meio ambiente facilitador.

$\mathrm{Na}$ ausência de um “ambiente suficientemente bom”, o bebê pode não adquirir a capacidade de usar objetos. Quando isso ocorre, o papel do analista é, então, o de fornecer um ambiente holding que possibilite à criança/paciente o desenvolvimento da capacidade de usar o analista, passando, assim, da relação ao uso do analista.

Do ponto de vista do desenvolvimento sequencial, tem-se primeiro a relação e depois o uso. Entre o relacionamento e o uso, existe a colocação, pelo sujeito, do objeto fora da área de seu controle onipotente, isto é, a percepção do objeto como fenômeno externo. Quando Winnicott fala de uso de um objeto, ele pressupõe como dada a relação de objeto, mas acrescenta novas características relacionadas à natureza e ao comportamento do objeto. Isso porque o objeto, para ser usado, deve ser necessariamente real, fazer parte da realidade partilhada, e não ser um feixe de projeções.

Ao se interessar pelo desenvolvimento e estabelecimento da capacidade de usar objetos, Winnicott (1968a/2005) esclarece que o sujeito precisa: 1) relacionar-se com o objeto; 2) encontrar o objeto; 3 ) destruir o objeto (com a não-retaliação deste); 4) perceber que o objeto sobrevive à destruição; e, só então, 5) usar o objeto.

Percebe-se que a mudança do relacionamento para o uso de objeto está relacionada à destruição do objeto pelo sujeito. Contudo, o bebê só pode destruir o objeto na medida que não há risco de este sucumbir. Se o bebê sente que precisa proteger o objeto devido à sua fragilidade, ele não o destruirá e não chegará a se relacionar com o objeto externo real, usando-o, amando-o ou odiando-o.

A destruição, em Winnicott, desempenha um papel na criação da realidade. Para que o bebê perceba o mundo objetivamente, ele deve experienciar o objeto que sobrevive à sua destrutividade. A sobrevivência do objeto conduz ao seu uso. E o uso do objeto conduz à separação de dois fenômenos distintos: a fantasia e a localização real do objeto fora da área de projeção. Assim, os objetos são destruídos por serem reais, e são reais por terem sido destruídos.

Ao transpor o desenvolvimento da capacidade de usar objetos para o setting analítico, observa-se que o analista precisa funcionar como "mãe suficientemente boa", permitindo-se ser alvo da agressividade do paciente e sobrevivendo a ela. A sobrevivência do analista, expressa principalmente na manutenção do setting analítico, permite que o paciente desenvolva a capacidade de usar objetos. O analista, nesse momento como mãe/ambiente, ao não retaliar o ataque, permite também que o paciente o coloque fora de sua área de onipotência, situação que instaura a realidade externa e a fantasia. 
Dias (2002) ressalta que o sobreviver significa dar continuidade ao que se inicia, preservando a qualidade da relação e do ambiente, sem retaliação. É, sobretudo, não sucumbir às turbulências próprias do estar vivo e do amadurecimento do paciente, inclusive as que incluem destruição. É manter o cuidado com o paciente, a despeito de seus próprios estados de ânimo, orientado pelas necessidades dele. Enfim, é manter-se vivo e permanecer sustentando a situação durante o tempo necessário para o processo do paciente.

Dias também chama a atenção para o fato de que, provavelmente, um dos maiores desafios para a capacidade de sobreviver do analista seja a situação do paciente que precisa regredir à dependência. Nessa situação, “deixar ser" pode significar "deixar não-ser". Nesse momento, a sobrevivência do analista é fundamental e não se pode esquecer o quanto é arriscado para o paciente expor-se à dependência e a um novo início de esperança.

Segundo Winnicott, muitos casos considerados inadequados para a análise "são realmente inadequados, se não soubermos lidar com as dificuldades surgidas na transferência em razão da falta essencial de uma verdadeira relação com a realidade externa" (WINNICOTT, 1945/2000, p.227). E ainda que "na prática psicanalítica, as mudanças positivas que ocorrem nessa área podem ser profundas. Elas não dependem do trabalho interpretativo, mas sim da sobrevivência do analista aos ataques, que envolve e inclui a ideia da ausência de uma mudança de qualidade para a retaliação." (WINNICOTT, 1968a/2005, p.175).

A questão da destruição e da sobrevivência do analista também pode ser ilustrada por Little:

"Pude renunciar gradualmente à minha onipotência e ao meu self falso, 'guardião', e, contando com seu 'apoio' ('holding'), reviver minha infância traumática. Eventualmente pude, de modo imaginoso, destruir e ser destruída por ele (novamente a mesma coisa) e depois, descobrindo que ambos havíamos sobrevivido, usá-lo e ser útil para ele.” (LITTLE, 1990, p.93)

Essa passagem de Little carrega um conteúdo complexo que condensa aspectos fundamentais de seu processo de análise. Safra (2004), ao realizar o estudo desse relato, revela que ele possui quatro momentos distintos do processo de Little: o tempo em que ela abdica de sua experiência de onipotência defensiva; a possibilidade de reviver a experiência traumática; o momento de se abrir para a experiência de destruir e de ser destruída; e, por fim, a possibilidade de usar o analista.

Essa experiência de destruir demonstra a aplicação das ideias de Winnicott acerca da importância da destruição e da sobrevivência do analista como elemento constitutivo que possibilita a colocação do analista fora da experiência 
de onipotência do paciente. Safra ressalta que a destruição, nesse caso, não está na dimensão da pulsão de morte e, sim, na dimensão constitutiva do sujeito. Uma dimensão que tem importância não apenas no processo de constituição como também no processo analítico de Little, a partir do qual a experiência de alteridade pôde acontecer.

Winnicott (1963a/1983), ao examinar a comunicação e a capacidade de se comunicar, mostra que a interpretação do analista precisa estar intimamente ligada às relações objetais do paciente. O autor afirma que a interpretação do analista, para ter efeito, deve estar relacionada à capacidade que o paciente tem de situar o analista fora da área dos fenômenos subjetivos. Quando o paciente ainda não pode situá-lo fora de seu alcance onipotente, o trabalho do analista deverá se fazer por outro meio, permitindo que essa mudança possa ocorrer.

Assim, Winnicott relaciona a interpretação com a capacidade de o paciente poder usar ou apenas se relacionar com o analista. Quando o paciente 'relaciona' com o analista, ele é visto como um objeto subjetivo. "Na medida em que o objeto é subjetivo, é desnecessário que a comunicação seja explícita.” (WINNICOTT, 1963a/1983, p.166). Isso leva Winnicott a concluir que: "uma psicoterapia de tipo profundo pode ser efetuada sem trabalho interpretativo" e que "no trabalho que estou descrevendo, o setting se torna mais importante do que a interpretação" (1955/2000, p.395).

Por outro lado, quando o analista passa de um objeto subjetivo para um objeto percebido objetivamente, a interpretação passa a ter efeito. Contudo, Winnicott chama a atenção para dois aspectos que ocorrem nesse caso: 1) a utilização e a apreciação pelo indivíduo dos modos de comunicação; e 2) o eu do indivíduo que não se comunica ou o núcleo pessoal do eu que é um isolado autêntico. Com isso, o autor se refere à fantasia de ser descoberto, à ameaça ao ser humano em sua necessidade de ser secretamente isolado e à "necessidade urgente de se comunicar e à necessidade ainda mais urgente de não ser decifrado” (WINNICOTT, 1963a/1983, p.168).

Para Winnicott, o sujeito estabelece um eu privado que não se comunica, mas, ao mesmo tempo, quer se comunicar e ser encontrado. O autor aponta que este é um sofisticado jogo de esconder, em que "é uma alegria estar escondido mas um desastre não ser achado” (idem, p.169). Com isso, Winnicott está chamando a atenção para o cuidado que se deve ter, na análise, com o fato de que, embora as pessoas se comuniquem e apreciem comunicar, é igualmente verdadeiro "que cada indivíduo é isolado, permanentemente sem se comunicar, permanentemente desconhecido, na realidade nunca encontrado" e que "no centro de cada pessoa há um elemento nãocomunicável, e isto é sagrado e merece muito ser preservado” (idem, p.170).

Winnicott afirma que a implicação disso para a técnica psicanalítica é o fato de o analista precisar admitir a não-comunicação como uma contribuição po- 
sitiva, devendo se interrogar se sua técnica permite ao paciente comunicar que não está se comunicando. Para Abram (1996), isso modifica os fundamentos da psicanálise. Enquanto Freud defendia a necessidade de o paciente te associar livremente e dizer tudo, Winnicott entende que o analista deve respeitar a necessidade do self privado do paciente de não se comunicar.

Ao examinar a técnica da interpretação, Winnicott afirma que "o propósito da interpretação deve incluir um sentimento que o analista tem de que foi feita uma comunicação que precisa ser reconhecida" (WINNICOTT, 1968a/2005, p.164). O analista, então, reflete de volta o que o paciente comunica, o que evita, inclusive, confusões e dá oportunidade de corrigir mal-entendidos.

No entanto, Winnicott alerta para as interpretações baseadas no material fornecido no dia determinado pelo paciente e não no conhecimento acumulado pelo analista. Essas são interpretações inúteis ao paciente. Nesses casos, “o analista pode parecer muito esperto, e o paciente pode expressar admiração, mas no final a interpretação correta é um trauma, que o paciente tem que rejeitar, porque não é sua” (WINNICOTT, 1960/1983, p.50).

Para Winnicott, uma interpretação correta e oportuna produz uma sensação no paciente de ser fisicamente seguro, que é mais real do que ser embalado ou posto no colo de fato. Por meio da interpretação, o analista "embala o paciente fisicamente no passado, ou seja, na época em que havia necessidade de estar no colo, quando o amor significava adaptação e cuidados físicos" (WINNICOTT, 1988, p.80).

Caminhando nesse sentido, Mano, ao utilizar a alegoria da estória dos Três Porquinhos, ilustra que a interpretação tem efeitos de experiência. A interpretação, enquanto sopro do analista, "tanto pode ser experimentada pelo paciente como uma brisa aconchegante e acalentadora, como também como um barulho que perfura a membrana do tímpano ou ainda como um vendaval ameaçador e desestruturante” (MANO, 2006, p.58).

Com relação ao momento da interpretação, Winnicott afirma que o analista deve demonstrar sua compreensão sobre o processo do paciente pela interpretação daquilo que o paciente está justamente em condições de admitir de maneira consciente.

“Acho que o mais cedo possível é o melhor momento para uma interpretação, quero dizer o momento mais cedo em que o material torne claro o que interpretar. Contudo, sou econômico em minha interpretação e se não estou certo do que interpretar não hesito em esperar por algum tempo. Ao fazê-lo me vejo envolvido em uma fase introdutória ou preparatória, brincando, construindo com a criança ou simplesmente sendo anulado, desperdiçado. Estaria preocupado, contudo, com uma coisa apenas, a procura do indício que torne possível a interpretação que seja apropriada 
para aquele momento, a interpretação que promova uma mudança de ênfase na transferência inconsciente.” (WINNICOTT, 1958/1983, p.112)

Winnicott afirma que devido a sua necessidade pessoal de interpretar demorou anos para se tornar "capaz de esperar e esperar a evolução natural da transferência que surge da confiança crescente do paciente na técnica e no setting psicanalíticos e evitar romper este processo natural efetuando interpretações" (1968b/2005, p.171). Para ele, se o analista puder esperar, o paciente chega ao entendimento de modo criativo.

\section{CONSIDERAÇÕES FINAIS}

A partir das ideias de Winnicott, ressaltaram-se alguns aspectos da relação transferencial que colocam em questão a técnica clássica da interpretação. Esclareceu-se que, muitas vezes, a interpretação está inabilitada, podendo levar a experiências e a estados confusionais. Assim, o trabalho de análise entra em uma situação de impasse, pois a técnica da interpretação empregada ameaça ainda mais o paciente, levando-o a experiências de desintegração e de fragmentação ainda maiores.

Nesse contexto, antes de interpretações, o objetivo da análise é proporcionar um ambiente suficientemente bom a partir do qual o paciente pode retomar o processo de constituição de si mesmo e da externalidade do mundo. Como consequência, os parâmetros clássicos para os quais se voltava o analista — como a interpretação verbal do complexo de Édipo, dos sonhos e dos atos falhos embora mantenham sua eficácia, passam a um plano secundário na intervenção clínica. O que amplia a clínica psicanalítica e o agir do analista, já que a intervenção deste não se reduz à interpretação: ela assinala, também, um acontecimento, uma experiência que se dá no campo transferencial.

Recebido em 29/4/2009. Aprovado em 13/10/2009.

\section{REFERÊNCIAS}

ABRAM, J. (1996). A linguagem de Winnicott. Dicionário das palavras e expressões utilizadas por Donald W. Winnicott. Rio de Janeiro: Revinter.

DIAS, E. O. (1999). Sobre a confiabilidade: decorrências para a prática clínica. Natureza Humana, 1(2), 283-322. Disponível em: http://www. centrowinnicott.com.br. Acesso em: 6/4/2009. . (2002). Da sobrevivência do analista. Natureza Humana, 4(2), 341-362. Disponível em: http://www.centrowinnicott.com.br. Acesso em: $6 / 4 / 2009$. 
FREUD, S. (1996) Edição standard brasileira das obras psicológicas completas de Sigmund Freud. Rio de Janeiro: Imago.

(1937). "Construções em análise”, v. XXIII, p.271-287.

LITTLE, M. I. (1990). Ansiedades psicóticas e prevenção: registro pessoal de uma análise com Winnicott. Rio de Janeiro: Imago.

MANO, B. C. B. (2006). O sopro do lobo: a noção de Eu-pele no manejo clínico, Cadernos de Psicanálise - CPRJ, 28(19), 57-69.

ROUDINESCO, E. \& PLON, M. (1998). Dicionário de psicanálise. Rio de Janeiro: Jorge Zahar.

SAFRA, G. (1995). Momentos mutativos em psicanálise: uma visão winnicottiana. São Paulo: Casa do Psicólogo.

(2003). O analista no lugar do sonho de si mesmo. Estudo de holding e interpretação. [dvd-vídeo]. São Paulo: Edições Sobornost.

(2004). Explorando as ansiedades psicóticas. [dvd-vídeo]. São Paulo: Edições Sobornost.

WINNICOTT, D. W. (1945/2000). “Desenvolvimento emocional primitivo", in Da pediatria à psicanálise: obras escolhidas. Rio de Janeiro: Imago. (1954/2000). “Retraimento e regressão”, p.347-354.

(1955/2000). "Aspectos clínicos e metapsicológicos da regressão no contexto psicanalítico”, p.374-392.

(1956/2000). “Formas clínicas da transferência”, p.393-398.

(1958/1983). "Análise da criança no período de lactência",

in $\mathrm{O}$ ambiente e os processos de maturação: estudos sobre a teoria do desenvolvimento emocional. Porto Alegre: Artmed.

(1960/1983). “Teoria do relacionamento paterno-infantil”, p.38-54.

(1962/1983). "Dependência no cuidado do lactente, no cuidado da criança e na situação psicanalítica”, p.225-233.

(1963a/1983). "Comunicação e falta de comunicação levando ao estudo de certos opostos”, p.163-174.

(1963b/1983). “Distúrbios psiquiátricos e processos de maturação infantil”, p.207-217.

(1961/2005). "Observações adicionais sobre a teoria do relacionamento parento-filial”, in Explorações psicanalíticas. Porto Alegre: Artmed Editora.

(1963c/2005). "O medo do colapso (breakdown)", p.70-76.

(1968a/2005). “A interpretação na psicanálise”, p.163-166.

(1968b/2005). "Sobre o uso de um objeto”, p.170-191. (1972/1991). Holding e interpretação. São Paulo: Martins Fontes. (1988). Natureza humana. Rio de Janeiro: Imago.

Lívia Milhomem Januário

liviamilhomem@hotmail.com

Maria Izabel Tafuri

mitafuri@unb.br 